\title{
4. SOBRE EL CARÁCTER TAXATIVO O DECLARATIVO DE LA RELACIÓN DE LAS MISIONES ATRIBUIDAS A LAS FUERZAS ARMADAS EN EL ART. 8 DE LA CONSTITUCIÓN
}

\author{
JOSÉ M. ${ }^{\mathrm{a}}$ LAFUENTE BALLE \\ Profesor Titular de Derecho Constitucional \\ Universidad de Girona
}




\section{SUMARIO}

INTRODUCCIÓN.-LA TESIS MAYORITARIA: LA TAXATIVIDAD DEL ART. 8.1.-LA TESIS dE FERnANDO LóPEZ RAMÓN.-UNA PROPUESTA DE REFORMA DEL ART. 8.1. 


\title{
4. SOBRE EL CARÁCTER TAXATIVO O DECLARATIVO DE LA RELACIÓN DE LAS MISIONES ATRIBUIDAS A LAS FUERZAS ARMADAS EN EL ART. 8 DE LA CONSTITUCIÓN
}

\author{
POR \\ JOSÉ M.a LAFUENTE BALLE \\ Profesor Titular de Derecho Constitucional \\ Universidad de Girona
}

\section{INTRODUCCIÓN}

\begin{abstract}
El objeto de la reflexión que me planteo en el presente trabajo tiene su origen en el debate que el Prof. LÓPEZ RAMÓN ${ }^{1}$ suscitó con motivo de defender su tesis sobre el carácter declarativo, es decir, no taxativo, de la enumeración de las misiones encomendadas a las Fuerzas Armadas en el art. 8.1 de la Constitución.
\end{abstract}

Esta postura venía a contradecir el criterio prácticamente unánime de la doctrina en favor del carácter taxativo de la relación del art. 8.1. La dogmática ha defendido que las misiones del art. 8.1 son clasificables según se refieran a la vertiente exterior o a la vertiente interior de la defensa nacional. Así, son misiones militares que se refieren a la defensa exterior, la garantía de la soberanía e independencia de España y la defensa de la

1 Fernando López RAMón: La Caracterización jurídica de las Fuerzas Armadas. Madrid, C.E.C. 1987, págs. 317 a 332; y "Principios de ordenación constitucional de las Fuerzas Armadas», en Estudios sobre la Constitución española. Homenaje al Prof. EDUARDO GARCÍA DE ENTERRÍA. Madrid, Ed. Civitas, 1991, págs. 2585 a 2587. Esta postura tuvo un precedente doctrinal, aunque menos argumentado en Manuel MARTínez SOSPEDRA: "Notas para un comentario del título Preliminar de la Constitución", en Estudios sobre la Constitución española de 1978. Valencia, Universidad de Valencia. Servicio de Publicaciones, 1980, págs. 80 a 82. 
integridad territorial cuando la amenaza tenga su origen en una potencia extranjera. En el otro lado, son misiones que se refieren a la defensa interior, la garantía de la soberanía de España frente a una rebelión, la defensa de la integridad territorial del Estado frente a un intento secesionista y la defensa del ordenamiento constitucional ${ }^{2}$.

A mi entender, aunque la tesis de la taxatividad del art. 8.1 tiene un sólido fundamento jurídico en el precepto constitucional, sucede que la práctica ha sobrepasado el texto de la norma constitucional que ha resultado, así, desfasada. Me refiero, en este sentido, por ejemplo, a las disposiciones del Gobierno por las que se acuerda encomendar a las Fuerzas Armadas labores de policía en la Expo 92 de Sevilla o en el trazado del Tren de alta velocidad Madrid-Sevilla. En mi opinión, estas labores de policía no son subsumibles en ninguna de las misiones que el art. 8.1 encomienda a las Fuerzas Armadas y, sin embargo, ello no ha significado -ni parece que vaya a significar- óbice alguno para que el Gobierno cese en esta práctica política.

Parto de la premisa de que la pretendida fuerza normativa de la Constitución depende de que la "Constitución real» y la "Constitución jurídica" converjan en una "Constitución integrada" $3, y$ de que para el estudio de esta convergencia, la Dogmática constitucional precisa de un análisis realista del Derecho en el que se utilicen métodos y criterios de interpretación no sólo jurídicos, sino también metajurídicos. Ello supuesto, se trata de analizar el grado de vigencia del art. 8.1, la adecuación de la realidad al texto de la norma y, sobre todo, el nivel de aceptación por los operadores jurídico-constitucionales.

\section{TESIS MAYORITARIA: LA TAXATIVIDAD DEL ART. 8.1}

La Doctrina constitucionalista de los últimos cinco años no ha variado la tendencia mayoritaria en favor de la taxatividad del art. 8.1 e incluso limitando su ejercicio a los supuestos de estados excepcionales, más concretamente al estado de sitio del art. 116.4, y de estado de guerra del art. 63.3. En este sentido se manifiestan profesores como CRESPO HELLíN ${ }^{4}$,

2 V. José M. ${ }^{a}$ LAfUente Balle: El Rey y las Fuerzas Armadas en la Constitución. Madrid, Ed. Revista de Derecho Privado, 1987, págs. 345 a 349.

3 V. KonRad Hesse: Estudios de Derecho Constitucional. Madrid, C.E.C., 1983, págs. 31 y 59 a 84 .

4 V. Félix CRESPo HeLLín: "El nuevo encuadre constitucional de las fuerzas y 
BLANCO ANDE ${ }^{5}$ y BLANCO VALDÉS ${ }^{6}$. Este último enumera distintos argumentos en defensa de su postura sobre la limitación del ejercicio por las Fuerzas Armadas de las misiones del art. 8.1 a una previa declaración del estado de sitio, a saber: la duplicidad que la Constitución consagra entre las funciones de las Fuerzas Armadas y las funciones de las Fuerzas y Cuerpos de seguridad (art. 104); de la Ley Orgánica de los estados de alarma, excepción y sitio, sus artículos 33.2 -designación gubernamental de una autoridad militar en el estado de sitio- y 32 - coincidencia de los supuestos de hecho del estado de sitio con las misiones encomendadas a las Fuerzas Armadas en el art. 8.1 de la Constitución-, y, en suma, la necesidad de interpretar de forma sistemática la Constitución y el resto de Ordenamiento Jurídico.

\section{TESIS DE FERNANDO LÓPEZ RAMÓN}

Frente a la tesis mayoritaria, el Prof. LÓPEZ RAMÓN defiende que el Gobierno, en virtud del art. 97.1, dispone de las Fuerzas Armadas sin la limitación procesal de que previamente se declare el estado de sitio o el estado de guerra 7: "El control de la adecuación entre el contenido de la misión constitucionalmente asignada a las Fuerzas Armadas y la concreta decisión del empleo de éstas, se desenvolverá por los cauces ordinarios de control político del Gobierno...n.

Pero además, este autor entiende que el art. 8.1 se refiere tan sólo a las funciones típicas de las Fuerzas Armadas, es decir aquellas que se concretan en intervenciones armadas. Junto a éstas, existirian otras funciones atípicas que en ningún caso pueden requerir el uso de las armas y que se refieren a situaciones catastróficas (arts. 22.1 de la Ley Orgánica de la Defensa Nacional y 2.2 de la Ley de Protección Civil).

cuerpos de seguridad", en Enrique Álvarez CONDE (editor): Diez años de régimen constitucional. Madrid, Tecnos, 1989, págs. 435 y 436.

5 Joaquín BLANCO ANDE: Defensa nacional y Fuerzas Armadas. Madrid, Ed. Dykinson, 1987, págs. 137 a 184.

6 Roberto L. Blanco Valdés: La Ordenación constitucional de la defensa. Madrid, Ed. Tecnos, 1988, págs. 61 a 76.

7 Fernando LóPEZ RAMÓN: La Caracterización..., cit., págs. 323 a 325; y Principios..., cit., págs. 2586-2587. 


\section{PROPUESTA DE REFORMA DEL ART. 8.1}

La Dogmática no ha replicado todavía la tesis del Prof. LÓPEZ RAMÓN sobre la constitucionalidad de la atribución a las Fuerzas Armadas de las que denomina funciones atípicas en situaciones catastróficas. A mi entender, no debería plantear problemas interpretativos porque el art. 30.4 de la Constitución no excluye a las Fuerzas Armadas de los deberes de la ciudadanía en los casos de grave riesgo, catástrofe o calamidad pública.

También coincido con el Prof. López Ramón en que el Gobierno no está limitado al proceso de declaración del estado de sitio para disponer de las Fuerzas Armadas para que ejerciten las misiones del art. 8.1. En mi opinión, la teoría contraria no se basa en un fundamento jurídico, sino en fundamentos de tipo psicológico. La tesis de la limitación procesal del Gobierno, sujetándola al iter del art. 116.3 para disponer de las Fuerzas Armadas, camufla una desconfianza injustificada a que el Gobierno mal use las Fuerzas Armadas y, por lo tanto, la fuerza de las armas en cualquier otro supuesto de hecho distinto de los tasados para el estado de sitio. Sin embargo, en un sistema parlamentario como el que establece la Constitución, el Gobierno se sustenta en la confianza del Congreso de los Diputados que, en cuanto que integrante de las Cortes Generales, representa al pueblo español.

Ahora bien, la tesis del Prof. López Ramón no resuelve, a mi entender un problema fundamental, a saber: El art. 32.1 de la Ley Orgánica 4/81 identifica los supuestos de hecho del estado de sitio con las misiones de las Fuerzas Armadas constitucionalizadas en el art. 8.1; $y$, sin embargo, el Prof. López Ramón afirma que el Gobierno no está limitado al proceso del estado de sitio para disponer de las Fuerzas Armadas para que ejerciten las misiones del art. 8.1. Ello significa que existen supuestos de hecho al margen de los del estado de sitio para los que el Gobierno puede disponer de las Fuerzas Armadas pero el Prof. López Ramón no menciona cuáles son estos supuestos y esto es precisamente la clave del conflicto.

A mi entender, no es discutible que para la disposición de las Fuerzas Armadas en la resolución de una amenaza "contra la soberanía o independencia de España, su integridad territorial o el ordenamiento constitucional» el Gobierno está sujeto al proceso de declaración del estado de sitio porque, sencillamente, así lo establece el art. 32 de la Ley Orgánica 4/81.

Ello no obstante, el Gobierno puede disponer de las Fuerzas Armadas $\sin$ las limitaciones procesales de la declaración del estado de sitio. $Y$ puede disponer no sólo para las funciones que el Prof. López Ramón denomina atípicas, sino también para las que conlleven el uso de las armas, 
siempre que el supuesto de hecho de la decisión sea distinto de los previstos en la Ley Orgánica 4/81 para el estado de sitio. Me refiero concretamente a los ejemplos antes expuestos de la vigilancia de la Expo 92 o del trazado del Tren de alta velocidad Madrid-Sevilla.

Se me podría objetar que esta opinión implica una vulneración del artículo 104.1. Sin embargo, las Fuerzas y Cuerpos de seguridad no monopolizan la misión de la seguridad ciudadana y además, en cuanto que dependientes del Gobierno, corresponde a éste la decisión política de encomendarles o no encomendarles una función.

La conclusión de este trabajo es obvia: si el Gobierno puede disponer de las Fuerzas Armadas no sólo para las misiones del art. 8.1, sería preferible no enumerarlas. Sin duda que esta postura, en razón al componente emocional que conlleva la Historia de las Fuerzas Armadas españolas, permite una crítica, además, política. Sin embargo, el principio de subordinación de la autoridad militar a la civil que se establece en el art. 97.1 de la Constitución debería ser suficiente para disipar cualquier desconfianza. 